\title{
KARAKTERISITIK MEKANIS CAMPURAN LASTON ATAS DENGAN PENAMBAHAN SERAT KARBON
}

\author{
Ewaldo Tanton ${ }^{1}$ dan Anissa Noor Tajudin ${ }^{2}$
}

\author{
${ }^{1}$ Program Studi Sarjana Teknik Sipil, Universitas Tarumanagara, Jl. Letjen S. Parman No.1 Jakarta \\ ewaldo.325160038@stu.untar.ac.id \\ ${ }^{2}$ Program Studi Sarjana Teknik Sipil, Universitas Tarumanagara, Jl. Letjen S. Parman No.1 Jakarta \\ anissat@ft.untar.ac.id
}

\begin{abstract}
The increasing number of vehicles but not followed by increasing the quality of pavement will cause many roads to be damaged. One of the efforts to improve the quality of road pavement is by adding various additional ingredients. For this research the method of mixing asphalt with carbon fiber uses the Dry-Mix method, where carbon fiber is directly mixed when cooking asphalt. By using a variation of 0,1\%;0,2\%;0,3\% and 0,4\% carbon fiber, and with asphalt content of 5,7\%. After obtaining asphalt mixture data, the research continued to determine the optimum carbon fiber content using the narrow range method. Then proceed to change the stability of Marshall into modulus then included in the KENPAVE program. Then the test results can be seen in the Nd and Nf values and the Nr value requirement of <2, which values are based on General Specifications of the Directorate General of Highways 2017 Edition. The results of this study have met all the requirements that have been set and based on the value of Nd and Nf it can be concluded that the use of carbon fiber asphalt mixture additives can be used in an effort to reduce the cost of asphalt treatment.
\end{abstract}

Keywords: Pavement; Carbon Fiber; Marshall Characterisics.

\begin{abstract}
ABSTRAK
Peningkatan jumlah kendaraan namun tidak diikuti dengan peningkatan kualitas perkerasan jalan akan menyebabkan banyak jalan yang mengalami kerusakan. Salah satu upaya untuk meningkatkan kualitas perkerasan jalan adalah dengan menambahkan bahan tambah yang bervariasi. Untuk penelitian ini cara pencampuran aspal dengan serat karbon menggunakan metode Dry-Mix, dimana serat karbon secara langsung dicampurkan pada saat memasak aspal. Dengan menggunakan variasi kadar serat karbon $0,1 \% ; 0,2 \% ; 0,3 \%$ dan 0,4\%, serta dengan kadar aspal 5,7\%. Setelah didapatkan data campuran aspal penelitian dilanjutkan untuk menentukan kadar serat karbon optimum dengan metode Narrow Range. Kemudian dilanjutkan mengubah stabilitas Marshall menjadi modulus kemudian dimasukkan ke dalam program KENPAVE. Kemudian hasil pengujian tersebut dapat dilihat pada nilai $\mathrm{Nd}$ dan $\mathrm{Nf}$ dan syarat nilai $\mathrm{Nr}$ yaitu <2, yang dimana nilai-nilai tersebut berdasarkan Spesifikasi Umum Direktorat Jendral Bina Marga Edisi 2017. Hasil dari penelitian ini telah memenuhi seluruh syarat yang telah ditetapkan dan berasarkan nilai $\mathrm{Nd}$ dan $\mathrm{Nf}$ dapat disimpulkan bahwa penggunaan serat karbon terhadap bahan tambahan campuran aspal dapat digunakan dalam usaha mengurangi biaya perawatan aspal.
\end{abstract}

Kata kunci: Perkerasan; Serat Karbon; Karakteristik Marshall.

\section{PENDAHULUAN}

Peningkatan jumlah kendaraan namun tidak diikuti dengan peningkatan kualitas perkerasan jalan akan menyebabkan banyak jalan yang mengalami kerusakan. Salah satu upaya untuk meningkatkan kualitas perkerasan jalan adalah dengan menambahkan bahan tambah yang bervariasi. Bahan tambah yang akan ditambahkan yaitu serat karbon. Serat karbon dipilih sebagai bahan tambah karena merupakan salah satu cara yang digunakan untuk mengurangi limbah hasil pabrik serat karbon. Limbah serat karbon yang ditambahkan dalam campuran dapat mengurangi biaya perawatan aspal dan limbah serat karbon dapat mengurangi keberadaan limbah pabrik serat karbon. Dalam penelitian ini penulis menggunakan serat karbon sebagai bahan tambah dengan kadar yang berbeda-beda yaitu sebesar $0,1 \% ; 0,2 \% ; 0,3 \%$; dan $0,4 \%$ dari berat total campuran. Diharapkan penambahan serat karbon akan menghasilkan campuran aspal yang lebih baik. 
Batasan masalah dalam penelitian ini adalah:

1. Karakteristik Marshall.

2. Agregat yang digunakan berasal dari PT.M3, Cikarang Barat, Bekasi.

3. Jenis campuran yang digunakan adalah AC-WC. Serat karbon sebagai bahan tambah digunakan sebanyak $0,1 \% ; 0,2 \% ; 0,3 \% ; 0,4 \%$ dari berat total campuran.

4. Aspal yang digunakan adalah aspal Shell dengan penetrasi 60/70.

5. Job mix design dan kadar aspal rencana menggunakan hasil penelitian terdahulu.

Rumusan masalah dalam penelitian ini adalah:

1. Bagaimana pengaruh penambahan serat karbon dengan persentase $0,1 \% ; 0,2 \% ; 0,3 \%$; dan $0,4 \%$ pada karakteristik volumetrik campuran?

2. Bagaimana pengaruh penambahan serat karbon dengan persentase $0,1 \% ; 0,2 \% ; 0,3 \%$; dan $0,4 \%$ pada kekuatan stabilitas campuran dan ketahanan campuran?

3. Bagaimana pengaruh penambahan serat karbon dengan persentase $0,1 \% ; 0,2 \% ; 0,3 \%$; dan $0,4 \%$ pada respons mekanistik campuran?

Tujuan dari penelitian ini adalah:

1. Untuk menganalisis pengaruh pengaruh penambahan serat karbon dengan persentase $0,1 \% ; 0,2 \% ; 0,3 \%$; dan $0,4 \%$ pada karakteristik volumetrik campuran.

2. Untuk menganalisis pengaruh penambahan serat karbon dengan persentase $0,1 \% ; 0,2 \% ; 0,3 \%$; dan $0,4 \%$ pada kekuatan stabilitas campuran dan ketahanan campuran.

3. Untuk menganalisis pengaruh pengaruh penambahan serat karbon dengan persentase $0,1 \% ; 0,2 \% ; 0,3 \% ;$ dan $0,4 \%$ pada respons mekanistik campuran.

\section{Perkerasan jalan}

Menurut (Tenriajeng, 2002), perkerasan jalan adalah campuran antara agregat yang memiliki fungsi untuk melayani beban lalu lintas. Agregat yang digunakan: batu pecah, batu belah, batu kali, hasil samping peleburan baja.. Sedangkan menurut (Saodang, 2005), perkerasan jalan merupakan gabungan dari komposiai bahan, yang berbeda elastisitasnya. Menurut (Amiruddin, 2012), perkerasan terbagi 2 jenis yaitu:

\section{Perkerasan kaku}

Menurut (Amiruddin, 2012), perkerasan kaku (rigid pavement) merupakan perkerasan yang menggunakan semen PC sebagai bahan pengikat agregat yang biasanya terbuat dalam bentuk plat beton empat persegi dan sifatnya kaku.

\section{Perkerasan lentur}

Menurut (Amiruddin, 2012), perkerasan lentur jalan (flexible pavement) pada umumnya adalah kombinasi antara aspal, agregat, filler serta aditif.

\section{Karakteristik campuran}

Ada beberapa karakteristik campuran:

\section{VFWA (Void Filled with Asphalt)}

Menurut (Hardiyatmo, 2015), persen rongga terisi aspal dalam campuran aspal dipadatakan adalah rasio antara volume aspal efektif terhadap volume rongga dalam agregat mineral. Untuk campuran aspal Asphalt Concrete-Wearing Course (AC-WC) hanya diperbolehkan 65\% kandungan volume udara yang ada (Departemen Pekerjaan Umum, 2018). Untuk mendapatkan rongga terisi aspal (VFWA) dapat ditentukan dengan persamaan:

$$
V F A=\frac{100(V M A-V I T M)}{V M A}
$$

dengan VITM = rongga di dalam campuran, VMA = rongga diantara mineral agregat.

2. VITM (Void in the Mix)

Menurut (Hardiyatmo, 2015), rongga di dalam campuran merupakan rasio antara volume rongga udara terhadap volume bulk di dalam campuran aspal. Untuk campuran aspal Asphalt Concrete-Wearing Course (AC-WC) hanya diperbolehkan 3,3\%-5,0\% kandungan volume udara yang ada (Departemen Pekerjaan Umum, 2018). Volume rongga udara dalam persen dapat ditentukan dengan rumus sebagai berikut:

$$
V I T M=100 \times \frac{V a}{V m b}
$$

dengan $\mathrm{Vmb}=$ volume bulk campuran dipadatkan, $\mathrm{Va}=$ volume rongga udara. 


\section{VMA (Void in Mineral Aggregate)}

Menurut (Wahjoedi, 2009), rongga diantara mineral agregat adalah volume rongga yang terdapat diantara butir-butir agregat dari suatu campuran beraspal yang telah dipadatkan, termasuk didalamnya adalah rongga udara dan rongga yang terisi aspal efektif, dinyatakan \% volume. Untuk campuran aspal Asphalt Concrete-Wearing Course (AC-WC) hanya diperbolehkan 15\% kandungan volume udara yang ada (Departemen Pekerjaan Umum, 2018). Perhitungan VMA terhadap campuran total dengan persamaan:

$$
V M A=100-\frac{G m b \times P s}{G s b}
$$

dengan Gsb = berat jenis bulk agregat, Gmb = berat jenis bulk campuran padat, Ps = kadar agregat

4. Stabilitas

Menurut (Wahjoedi, 2009), stabilitas adalah kemampuan suatu campuran aspal untuk menerima beban sampai terjadi kelelehan plastis yang dinyatakan dalam kilogram. Nilai stabilitas diperoleh dari hasil pembacaan alat tes Marshall.

\section{Kelelehan}

Menurut (Wahjoedi, 2009), kelelehan adalah perubahan bentuk plastis suatu campuran aspal yang terjadi akibat beban sampai batas runtuh yang dinyatakan dalam $\mathrm{mm}$ atau 0,01 ". Seperti halnya cara memperoleh nilai stabilitas, nilai flow merupakan nilai dari masing-masing yang ditunjukkan oleh jarum.

\section{Marshall Quotient}

Menurut (Wahjoedi, 2009), Marshall Quotient adalah angka pendeketatan yang hampir menunjukan nilai kekakuan suatu campuran beraspal dalam menerima beban. Semakin tinggi nilai Marshall Quotient, maka kemungkinan akan semakin tinggi kekakuan suatu campuran. Marshall Quotient dapat dihitung sebagai berikut:

$$
M Q=\frac{\text { Stabilitas }}{\text { Flow }}
$$

dengan Stabilitas $=$ stabilitas campuran, Flow $=$ kelelehan campuran.

\section{Serat karbon}

Serat karbon adalah bahan yang terdiri dari serat yang sangat kecil dengan diameter serat $\pm 7 \mu \mathrm{m}$ dan sebagian besar terdiri dari atom karbon. Karakteristik dari serat karbon antara lain: tegangan tarik $360 \pm 50 \mathrm{~kg} / \mathrm{mm}^{2}$, modulus elastisitas $23.500 \pm 1.000 \mathrm{~kg} / \mathrm{mm}^{2}$, massa jenis $1,75 \pm 0,2 \mathrm{~g} / \mathrm{cm}^{3}$ (Sutrisno, 2015). Menurut (Shanbara, 2011), penggunaan serat karbon menunjukkan hasil yang konsisten dan ditemukan bahwa penambahan serat mempengaruhi sifat-sifat campuran aspal.

\section{Fungsi transfer}

Menurut (Departemen Pekerjaan Umum, 2017), fungsi transfer adalah suatu fungsi yang menghubungkan respons perkerasan terhadap beban (berupa tegangan atau regangan) dengan kinerja perkerasan (berupa retak lelah dan deformasi permanen). Berikut ini adalah fungsi transfer yang digunakan pada penelitian ini:

\section{Retak lelah lapis beraspal}

Untuk aspal konvensional pada perkerasan dengan beban sedang hingga berat, fungsi transfer yang menunjukkan hubungan antara regangan tarik maksimum akibat beban tertentu dan jumlah repetisi izin beban tersebut untuk kinerja retak lelah adalah:

$$
N=R F\left[\frac{6918 \times(0,856 V b+1,08)}{S_{m i x}^{0,36} \mu \varepsilon}\right]^{5}
$$

dengan $\mu \varepsilon=$ regangan tarik akibat beban (microstrain), $\mathrm{Vb}=$ volume aspal dalam campuran, Smix $=$ modulus campuran aspal, $\mathrm{RF}=$ faktor reliabilitas.

\section{Deformasi permanen}

Pembatasan regangan tekan elastik pada permukaan tanah dasar akan mengendalikan regangan tekan elastik pada lapisan-lapisan di atasnya sehingga total regangan plastik akan juga terkendali. Model pembatasan regangan pada tanah dasar sebagai pengendali kinerja berdasarkan kriteria deformasi permanen adalah:

$$
N=\left[\frac{9300}{\mu \varepsilon}\right]^{7}
$$

dengan $\mathrm{N}=$ jumlah repetisi izin beban, $\mu \varepsilon=$ regangan tekan pada permukaan tanah dasar (microstrain). 


\section{METODE PENELITIAN}

Alur atau tahapan dari penelitian ini tertera dalam bentuk diagram pada Gambar 1.

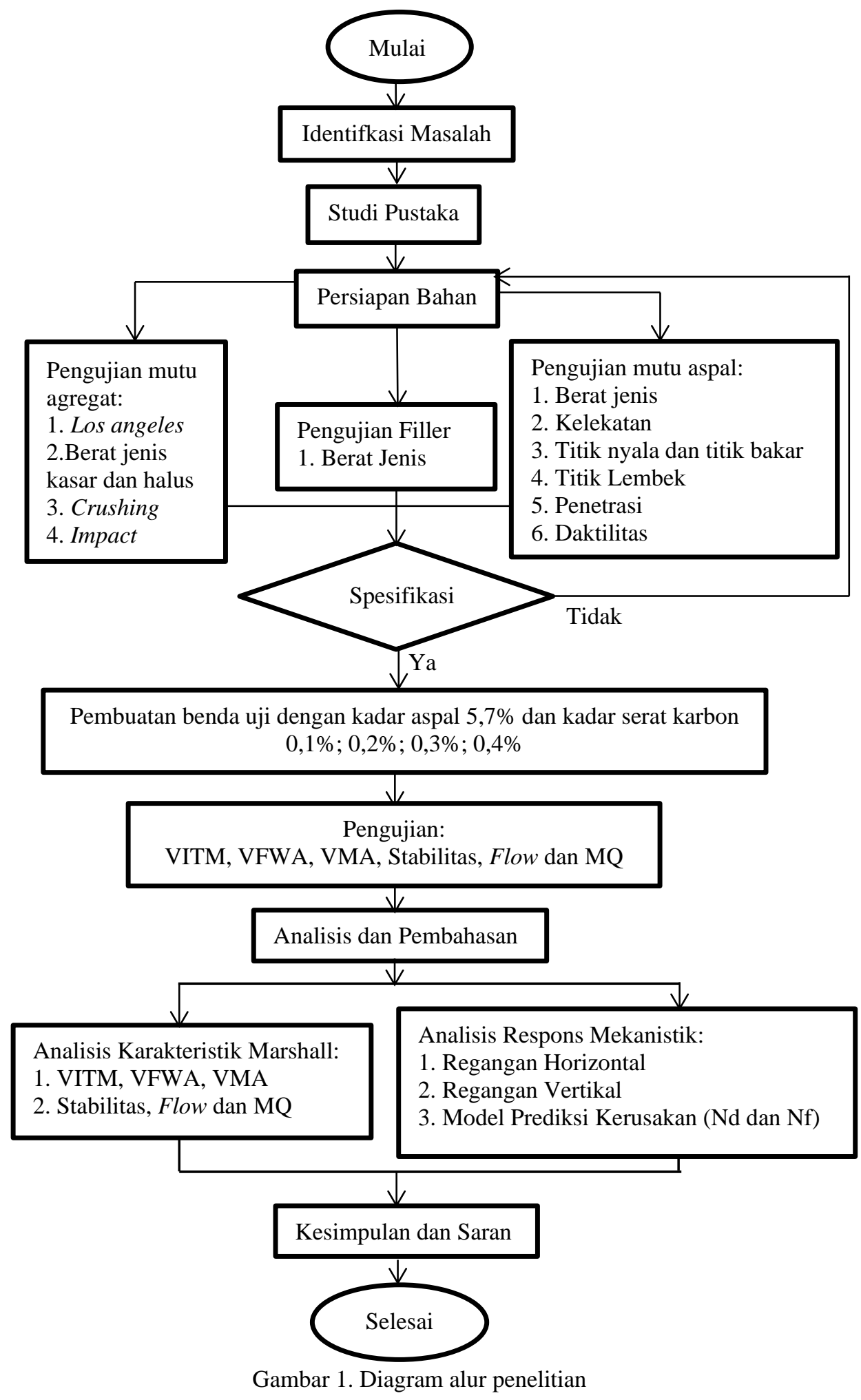

Pada penelitian ini dilaksanakan di laboratorium PT. Marga Maju Mapan, dengan menggunakan tipe AC-WC (Asphalt Concrete - Wearing Course) dengan panduan Binamarga dan pencampuran serat karbon menggunakan metode DryMix. Agregat yang digunakan berasal dari PT. Marga Maju Mapan dan disaring dan dibersihkan di laboratirum Perkerasan Universitas Tarumanagara. 
Dalam penelitian ini rancangan gradasi dan komposisi agregat untuk campuran dapat dilihat pada tabel 1.

Tabel 1. Rancangan gradasi dan komposisi agregat untuk campuran

\begin{tabular}{|c|c|c|c|c|c|c|c|c|}
\hline \multirow[t]{2}{*}{ Bahan } & \multicolumn{2}{|c|}{ Saringan } & \multicolumn{3}{|c|}{ Spesifikasi Lolos (\%) } & \multirow{2}{*}{$\begin{array}{c}\text { Tinggal } \\
\text { Di Atas } \\
(\%)\end{array}$} & \multicolumn{2}{|c|}{ Jumlah Menurut Spesfikasi } \\
\hline & $\mathrm{mm}$ & \# & Min & Max & Target & & Tinggal $(\%)$ & (gram) \\
\hline \multirow{3}{*}{$\begin{array}{c}\text { Agregat } \\
\text { Kasar } \\
(42,25 \%) \\
\end{array}$} & 12,7 & $1 / 2 "$ & 90 & 100 & 96,5 & 3,5 & 3,5 & 42 \\
\hline & 9,52 & $3 / 8 "$ & 77 & 90 & 83,8 & 16,2 & 12,7 & 153 \\
\hline & 4,76 & $\# 4$ & 53 & 69 & 57,8 & 42,2 & 26 & 312 \\
\hline \multirow{6}{*}{$\begin{array}{c}\text { Agregat } \\
\text { Halus } \\
(51,67 \%)\end{array}$} & 2,36 & $\# 8$ & 33 & 53 & 38,9 & 61,2 & 18,9 & 227 \\
\hline & 1,18 & $\# 16$ & 21 & 40 & 25,9 & 74,1 & 13 & 156 \\
\hline & 0,59 & \#30 & 14 & 30 & 19,9 & 80,2 & 6 & 72 \\
\hline & 0,279 & $\# 50$ & 9 & 22 & 14,6 & 85,5 & 5,3 & 64 \\
\hline & 0,149 & \#100 & 6 & 15 & 9,9 & 90,1 & 4,7 & 56 \\
\hline & 0,074 & $\# 200$ & 4 & 10 & 6,1 & 93,9 & 3,8 & 45 \\
\hline $\begin{array}{c}\text { Filler } \\
(6,08 \%)\end{array}$ & PAN & & & & & 100 & 6,1 & 73 \\
\hline
\end{tabular}

\section{Rancangan jumlah benda uji}

Dalam penelitian ini serat karbon berfungsi sebagai bahan tambah yang akan ditambahkan dalam campuran AC-WC, jumlah serat karbon yang telah dirancang terlampir dalam tabel 2.

Tabel 2. Rancangan jumlah benda uji

\begin{tabular}{ccc}
\hline No & Jenis Benda Uji & Jumlah \\
\hline 1 & $\begin{array}{c}\text { Benda uji perendaman standar dengan } \\
\text { variasi serat karbon 0,1\% }\end{array}$ & $5 \mathrm{BU}$ \\
2 & $\begin{array}{c}\text { Benda uji perendaman standar dengan } \\
\text { variasi serat karbon 0,2\% }\end{array}$ & $5 \mathrm{BU}$ \\
3 & $\begin{array}{c}\text { Benda uji perendaman standar dengan } \\
\text { variasi serat karbon } 0,3 \%\end{array}$ & $5 \mathrm{BU}$ \\
4 & $\begin{array}{c}\text { Benda uji perendaman standar dengan } \\
\text { variasi serat karbon } 0,4 \%\end{array}$ & $5 \mathrm{BU}$ \\
\hline & Total Benda Uji & $20 \mathrm{BU}$ \\
\hline
\end{tabular}

\section{Pengujian Marshall}

Setelah pembuatan benda uji selesai maka dilanjutkan dengan uji coba Marshall untuk mengetahui nilai VFWA, VITM, VMA, stabilitas, flow, Marshall Quotient (MQ) dari campuran.

\section{Penentuan kadar serat karbon optimum dengan metode Narrow Range}

Metode Narrow Range dapat digunakan untuk menentukan kadar serat karbon optimum, yaitu dengan menempatkan nilai karakteristik Marshall campuran aspal dan batas-batas spesifikasi yang telah ditentukan pada grafik hubungan antara kadar serat karbon dengan nilai karakteristik Marshall.

\section{Evaluasi perkerasan}

Perhitungan evaluasi perkerasan pada bagian desain Manual Perkerasan Jalan 2017 dengan menggunakan program KENPAVE, yaitu menempatkan parameter pada perkerasan yang akan dimasukkan program kemudian dihasilkan nilai regangan tarik horisontal dan regangan tekan vertikal yang dikonversikan menjadi nilai repetisi izin leleh dan repitis deformasi permanen dan dibandingkan dengan nilai repetisi beban rencana.

\section{HASIL DAN PEMBAHASAN}

\section{Karakterisktik bahan penyusun campuran}

Agregat serta filler yang digunakan untuk campuran beton aspal (AC-WC) berasal dari Cibarusa, Bekasi, Jawa Barat. Serat karbon yang digunakan merupakan serat yang didapatkan dari online shop. Aspal yang digunakan adalah aspal Shell pen 60/70. Hasil pemeriksaan bahan penyusun campuran disajikan pada Tabel 3 dan Tabel 4. Karakteristikkarakteristik yang diuji telah memenuhi Spesifikasi Umum Direktorat Jendral Bina Marga Edisi 2017. 
Tabel 3. Hasil pemeriksaan fisik agregat

\begin{tabular}{|c|c|c|c|c|c|c|}
\hline No & \multicolumn{2}{|c|}{ Jenis Pengujian } & Syarat & Hasil & Satuan & Keterangan \\
\hline \multicolumn{7}{|c|}{ A. Agregat Kasar } \\
\hline 1 & \multicolumn{2}{|c|}{ Abrasi dengan mesin Los Angeles } & Maks 40 & 32,962 & $\%$ & Memenuhi \\
\hline 2 & \multicolumn{2}{|c|}{ Kelekatan Terhadap Aspal } & Min 95 & 98 & $\%$ & Memenuhi \\
\hline 3 & \multicolumn{2}{|c|}{ Berat Jenis Semu } & Min 2,5 & 2,69 & $\mathrm{~g} / \mathrm{cm}^{3}$ & Memenuhi \\
\hline 4 & \multicolumn{2}{|c|}{ Absorpsi } & Maks 3 & 0,55 & $\%$ & Memenuhi \\
\hline \multicolumn{7}{|c|}{ B. Agregat Halus } \\
\hline 1 & \multicolumn{2}{|c|}{ Absorpsi } & Maks 3 & 2,88 & $\%$ & Memenuhi \\
\hline 2 & \multicolumn{2}{|c|}{ Berat Jenis Semu } & Min 2,5 & 2,72 & $\mathrm{~g} / \mathrm{cm}^{3}$ & Memenuhi \\
\hline \multicolumn{7}{|c|}{ C. Filler } \\
\hline \multirow[t]{8}{*}{1} & \multicolumn{2}{|c|}{ Berat Jenis Semu } & Min 2,5 & 2,5 & $\mathrm{~g} / \mathrm{cm}^{3}$ & Memenuhi \\
\hline & \multicolumn{6}{|c|}{ Tabel 4. Hasil pemeriksaan fisik aspal } \\
\hline & No & Jenis Pengujian & \multicolumn{2}{|c|}{ Spesfikasi } & \multicolumn{2}{|c|}{ Hasil } \\
\hline & 1 & Penetrasi pada $25^{\circ} \mathrm{C}(\mathrm{dmm})$ & \multicolumn{2}{|c|}{$60-70$} & \multicolumn{2}{|c|}{68} \\
\hline & 2 & Titik Lembek $\left({ }^{\circ} \mathrm{C}\right)$ & \multicolumn{2}{|c|}{$\geq 48$} & \multicolumn{2}{|c|}{52} \\
\hline & 3 & Daktilias pada $25^{\circ} \mathrm{C}(\mathrm{cm})$ & \multicolumn{2}{|c|}{$\geq 100$} & \multicolumn{2}{|c|}{111,2} \\
\hline & 4 & Titik Nyala $\left({ }^{\circ} \mathrm{C}\right)$ & \multicolumn{2}{|c|}{$\geq 232$} & \multicolumn{2}{|c|}{323} \\
\hline & 5 & Berat Jenis $\left(\mathrm{gr} / \mathrm{cm}^{3}\right)$ & \multicolumn{2}{|c|}{$\geq 1,0$} & \multicolumn{2}{|c|}{1,036} \\
\hline
\end{tabular}

\section{Karakterisktik Marshall campuran}

Hasil uji Marshall dengan penggunaan agregat pada berbagai kadar aspal dipresentasikan pada tabel 5.

Tabel 5. Hasil pengujian Marshall dengan variasi serat karbon

\begin{tabular}{cccccc}
\hline Kriteria & Spesfikasi & $\begin{array}{c}0,1 \% \text { Serat } \\
\text { Karbon }\end{array}$ & $\begin{array}{c}0,2 \% \text { Serat } \\
\text { Karbon }\end{array}$ & $\begin{array}{c}0,3 \% \text { Serat } \\
\text { Karbon }\end{array}$ & $\begin{array}{c}0,4 \% \text { Serat } \\
\text { Karbon }\end{array}$ \\
\hline VFWA & $>65 \%$ & $80,51 \%$ & $77,46 \%$ & $75,89 \%$ & $67,36 \%$ \\
VITM & $3-5 \%$ & $3,06 \%$ & $3,69 \%$ & $4,01 \%$ & $5,99 \%$ \\
VMA & $>15 \%$ & $15,72 \%$ & $16,35 \%$ & $16,62 \%$ & $18,34 \%$ \\
Stabilitas & $>800 \mathrm{~kg}$ & $1426 \mathrm{~kg}$ & $1319 \mathrm{~kg}$ & $1222 \mathrm{~kg}$ & $1202 \mathrm{~kg}$ \\
Flow & $>3 \mathrm{~mm}$ & $4,10 \mathrm{~mm}$ & $4,40 \mathrm{~mm}$ & $4,45 \mathrm{~mm}$ & $4,47 \mathrm{~mm}$ \\
MQ & $>250 \mathrm{~kg} / \mathrm{mm}$ & $350 \mathrm{~kg} / \mathrm{mm}$ & $301 \mathrm{~kg} / \mathrm{mm}$ & $276 \mathrm{~kg} / \mathrm{mm}$ & $270 \mathrm{~kg} / \mathrm{mm}$ \\
\hline
\end{tabular}

Setelah melakukan pengujian, perhitungan, dan analisis terhadap karakteristik dan sifat fisik dari aspal dan agregat serta campuran, maka pada tahap ini akan dibahas mengenai pengertian dari karakterstik Marshall dan ditampilkan data-data hasil pengujian tersebut dalam bentuk grafik pada Gambar 2. 
EISSN $2622-545 \mathrm{X}$

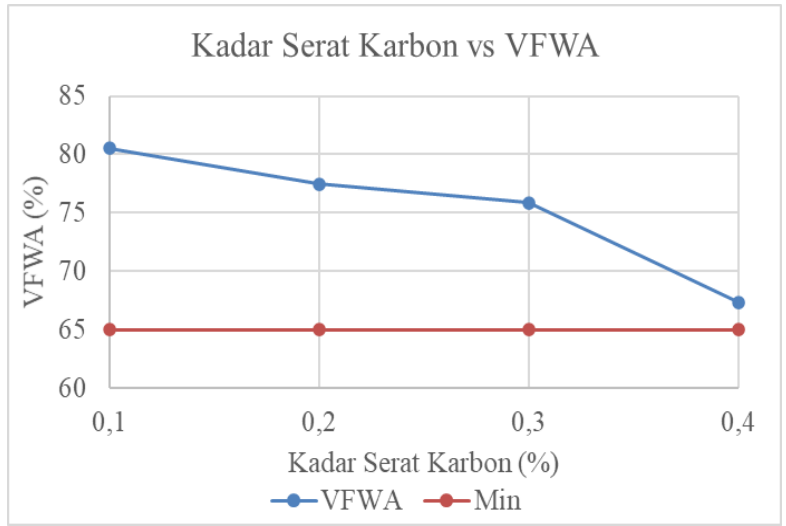

(a)

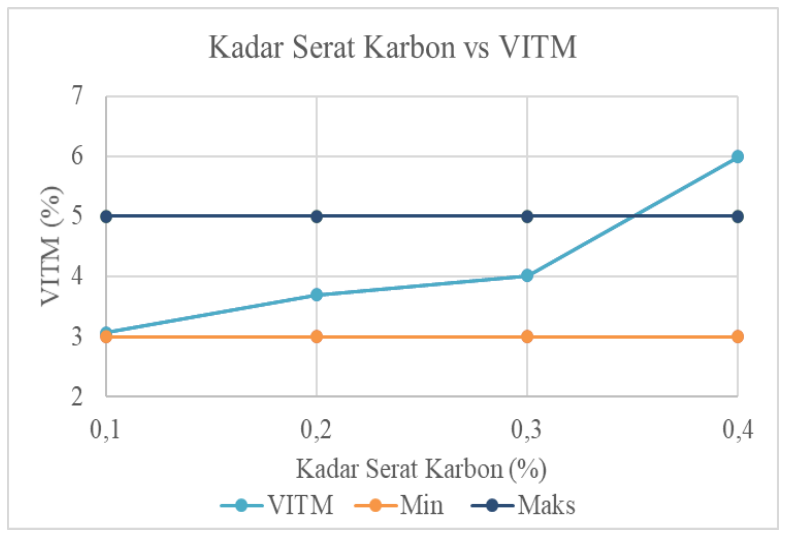

(c)

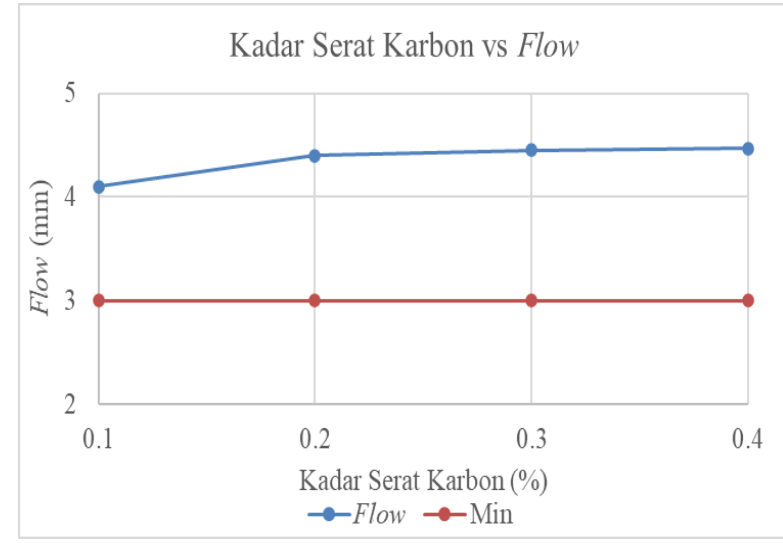

(e)

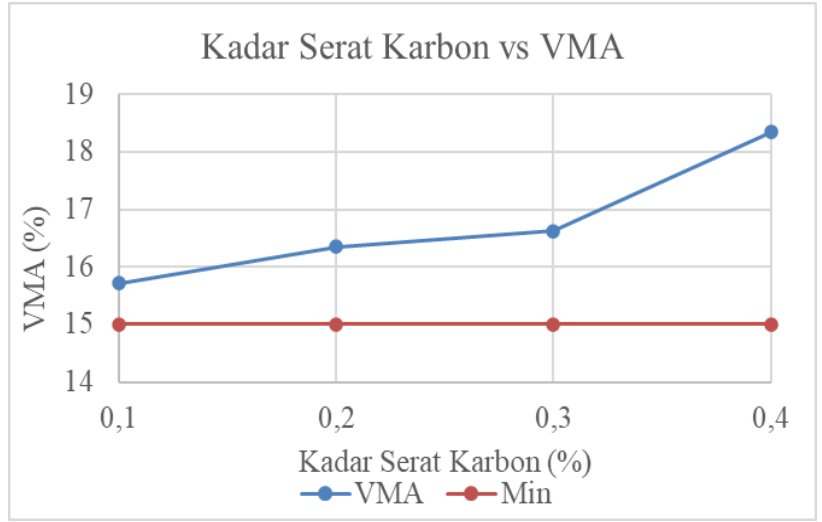

(b)

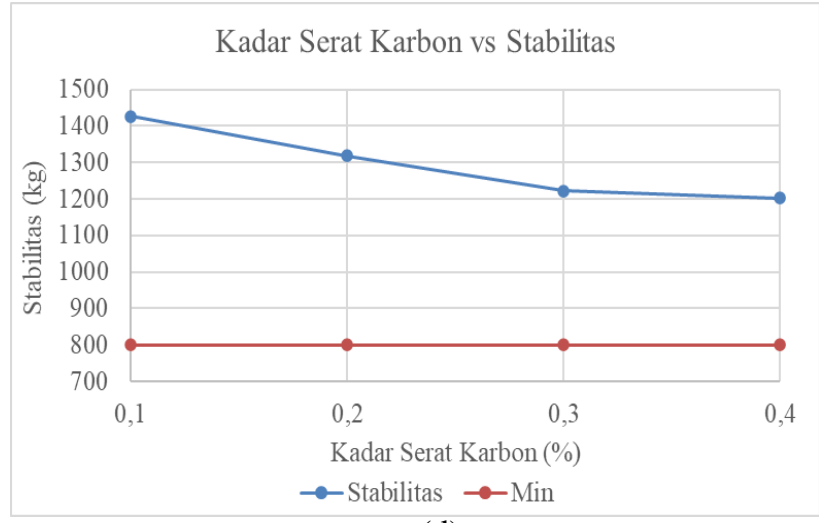

(d)

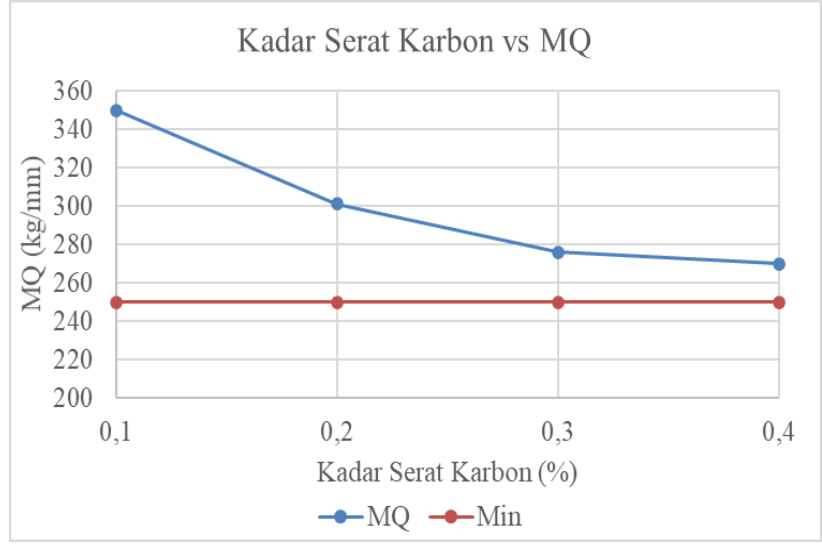

(f)

Gambar 2. Hubungan kadar serat karbon (a) VFWA, (b) VMA, (c) VITM, (d) Stabilitas, (e) Flow, (f) MQ

Berdasarkan Gambar 2 dapat disimpulkan bahwa nilai VFWA, VMA, stabilitas, flow dan MQ sudah memenuhi spesifikasi yang telah ditentukan. Namun pada nilai VITM, ada yang berada diatas spesifikasi yang telah ditentukan. Hal ini terjadi pada pengujian yang dilakukan dengan kadar serat karbon 0,4\%, data VITM yang didapatkan berada di atas batas maksimal sehingga kadar serat karbon optimum tidak bisa ditentukan karena tidak bisa didapat nilai tengah dari rentang kadar serat karbon yang memenuhi semua sifat campuran. Metode yang digunakan adalah metode Narrow Range agar kadar serat karbon optimum bisa didapatkan.

\section{Penentuan kadar serat karbon optimum dengan metode Narrow Range}

Pada Gambar 3 menunjukkan wilayah dari kadar aspal yang nilai masing-masing karakteristik campuran memenuhi spesifikasi Bina Marga sehingga kadar serat karbon optimum dapat ditentukan 


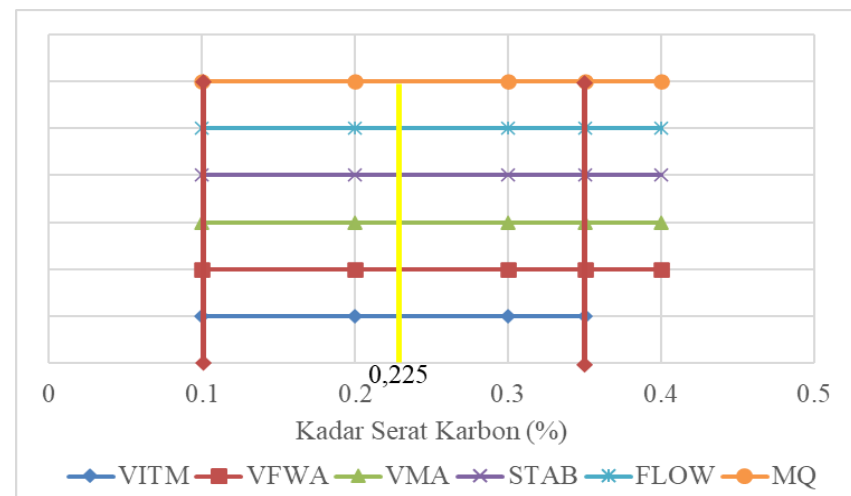

Gambar 3. Narrow Range kadar serat karbon

Berdasarkan Gambar 3, kadar serat karbon optimum diambil pada nilai tengah kadar aspal yang memenuhi syarat dan dilakukan pembulatan ke atas. Didapatkan kadar serat karbon optimum yaitu sebesar 0,225\%.

\section{Modulus elastisitas}

Nilai modulus elastisitas pada penelitian ini berdasarkan nilai stabilitas Marshall yang didapat dari data laboratorium yang kemudian dikorelasi menggunakan grafik korelasi stabilitas Marshall dengan modulus. Berikut grafik korelasi yang digunakan dalam menentukan nilai modulus seperti pada Gambar 4.

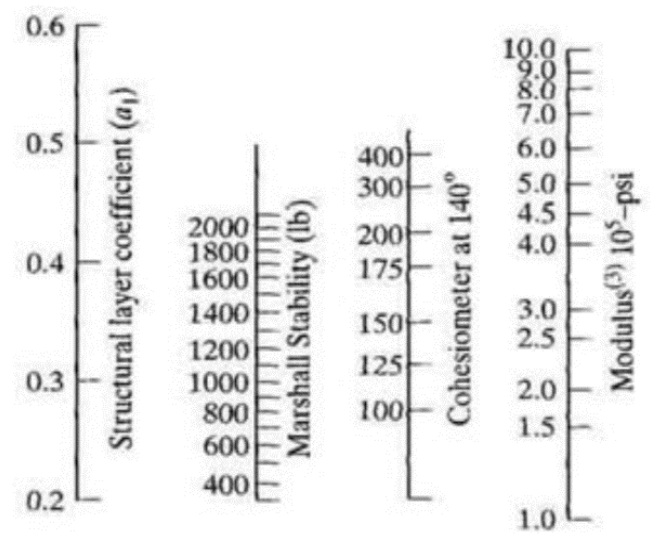

Gambar 4 Grarik korelasi stabilitas Marshall dan modulus

Lalu, jika grafik tersebut ditransfer dalam bentuk data tabel, akan seperti pada Tabel 6.

Tabel 6. Hubungan stabilitas Marshall dengan modulus

\begin{tabular}{cc}
\hline Stabilitas Marshall (lb) & Modulus $\left(10^{5} \mathrm{psi}\right)$ \\
\hline 300 & 1,1 \\
400 & 1,2 \\
500 & 1,3 \\
600 & 1,4 \\
700 & 1,5 \\
900 & 1,9 \\
1000 & 2,1 \\
1100 & 2,25 \\
1200 & 2,4 \\
1300 & 2,7 \\
1400 & 3 \\
1500 & 3,2 \\
1600 & 3,5 \\
1700 & 3,8 \\
1800 & 3,95 \\
1900 & 4,1 \\
2000 & 4,25 \\
2100 & 4,5 \\
\hline
\end{tabular}


Kemudian data Tabel 6 diplot dalam grafik dan dilakukan pendekatan regresi untuk mendapatkan persamaan garisnya seperti pada Gambar 5

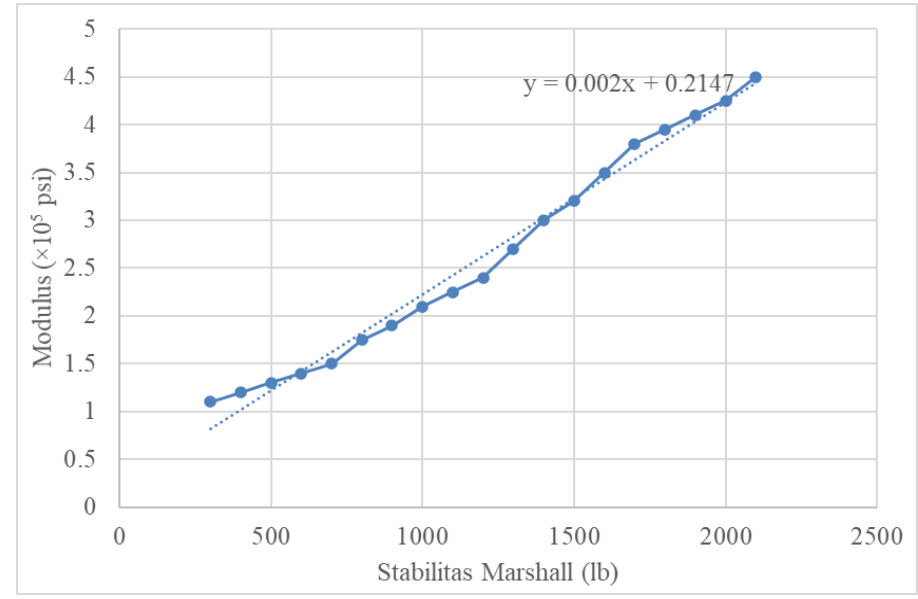

Gambar 5. Grafik regresi hubungan stabilitas Marshall dengan modulus

Dari Gambar 5, didapat persamaan garis $\mathrm{y}=0,002 \mathrm{x}+0,2147$. Kemudian persamaan tersebut digunakan untuk melakukan pendekatan agar nilai stabilitas Marshall dari data lab dapat dikonversi menjadi nilai modulus. Hasil korelasi dapat dilihat pada Tabel 7.

Tabel 7. Konversi stabilitas Marshall menjadi modulus

\begin{tabular}{cccccc}
\hline Kadar Serat Karbon & Marshall (kg) & Marshall (lb) & Modulus (psi) & Modulus (Mpa) & Modulus (Kpa) \\
\hline 0,1 & 1426 & 3144,33 & 650336 & 4485,075862 & 4485075,862 \\
0,2 & 1319 & 2908,395 & 603149 & 4159,648276 & 4159648,276 \\
0,3 & 1222 & 2694,51 & 560372 & 3864,634483 & 3864634,483 \\
0,4 & 1202 & 2650,41 & 551552 & 3803,806897 & 3803806,897 \\
\hline
\end{tabular}

\section{Respons mekanistik}

Respons mekanistik yang dianalisis dalam penelitian ini adalah regangan vertikal dan horizontal. Nilai-nilai yang perlu dimasukkan kedalam program KENPAVE antara lain adalah nilai modulus, poisson ratio, dan tebal di setiap lapisan. Hasil dari program KENPAVE untuk nilai regangan vertikal dan regangan horizontal pada lapisan FFF1 disajikan pada Tabel 8 dan Gambar 6.

Tabel 8. Nilai regangan horizontal dan regangan vertikal pada perkerasan FF1

\begin{tabular}{ccc}
\hline Kadar Serat Karbon & Regangan Vertikal & Regangan Horizontal \\
\hline 0,1 & $3,95 \mathrm{E}-04$ & $2,47 \mathrm{E}-04$ \\
0,2 & $3,98 \mathrm{E}-04$ & $2,48 \mathrm{E}-04$ \\
0,3 & $4,00 \mathrm{E}-04$ & $2,48 \mathrm{E}-04$ \\
0,4 & $4,00 \mathrm{E}-04$ & $2,48 \mathrm{E}-04$ \\
\hline
\end{tabular}

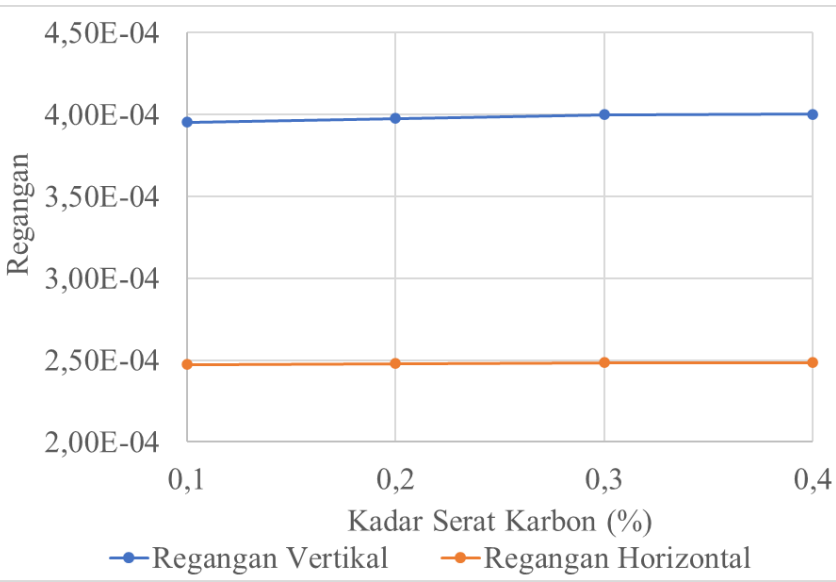

Gambar 6. Grafik hubungan kadar serat karbon dengan regangan horizontal dan regangan vertikal 
Berdasarkan Tabel 8 dan Gambar 6, semakin tinggi kadar serat karbon dalam campuran maka semakin besar juga nilai regangan vertikal dan horizontal yang didapatkan. Pada penelitian ini nilai regangan vertikal dan horizontal akan dibandingkan dengan nilai stabilitas campuran, dan didapatkan bahwa nilai regangan vertikal dan horizontal berbanding terbalik dengan nilai stabilitas campuran. Dimana nilai regangan vertikal dan horizontal terus bertambah sesuai dengan penambahan kadar serat karbon sedangkan nilai stabilitas campuran terus menurun seiring bertambahnya kadar serat karbon.

Nilai regangan vertikal kemudian akan dimasukkan ke dalam rumus prediksi kerusakan alur (Rutting) yang disimbolkan dengan $\mathrm{Nd}$, sedangkan nilai regangan horizontal akan dimasukkan ke dalam rumus prediksi kerusakan retak lelah (Fatigue) yang disimbolkan dengan Nf. Nilai Nf dan $\mathrm{Nd}$ menunjukan batas repetisi maksimum agar kerusakan alur tidak terjadi. Nilai Nd dan Nf pada perkerasan FFF1 disajikan pada Tabel 9 dan Gambar 7 dan 8.

Tabel 9. Nilai Nf dan Nd pada perkerasan FFF1

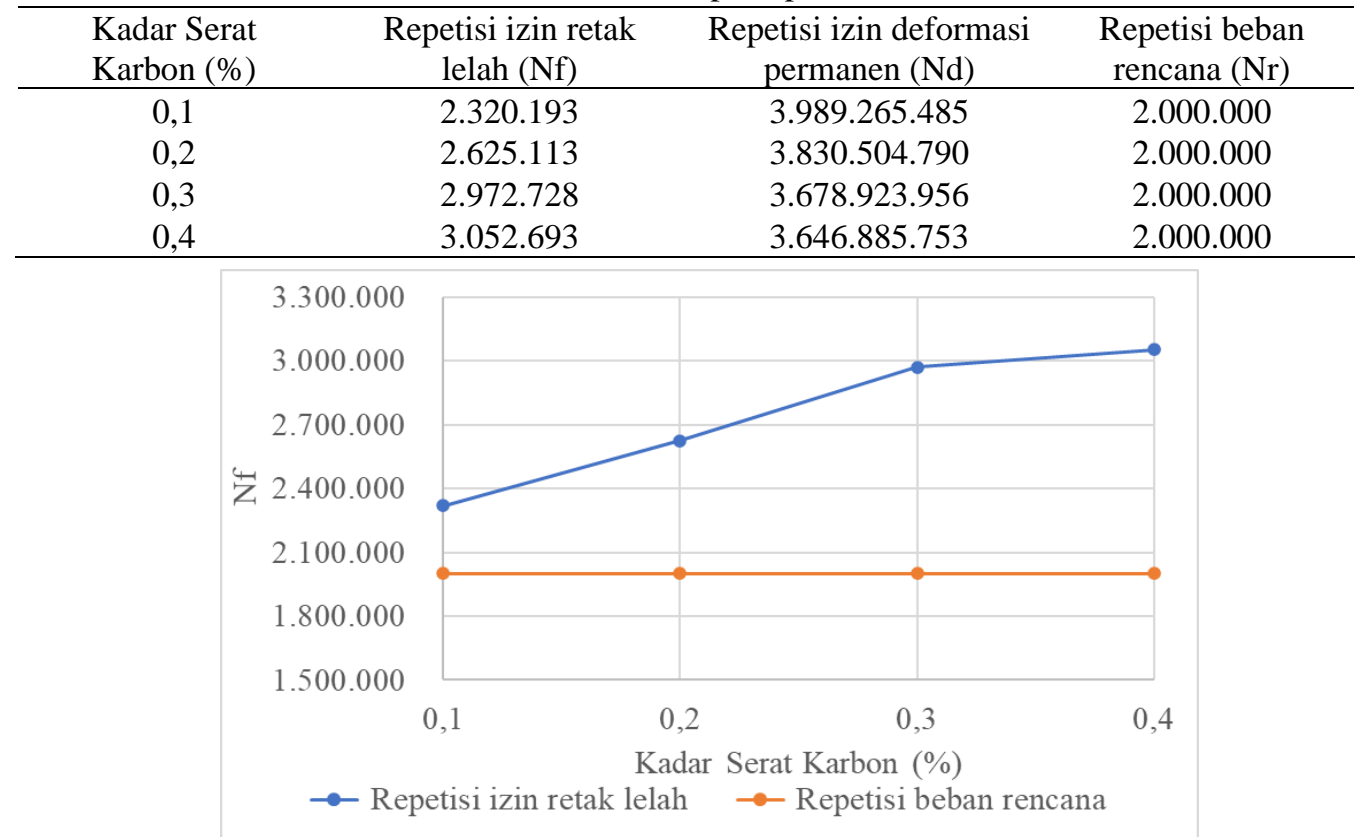

Gambar 7. Hubungan kadar serat karbon dalam campuran dengan nilai Nf pada perkerasan FFF1

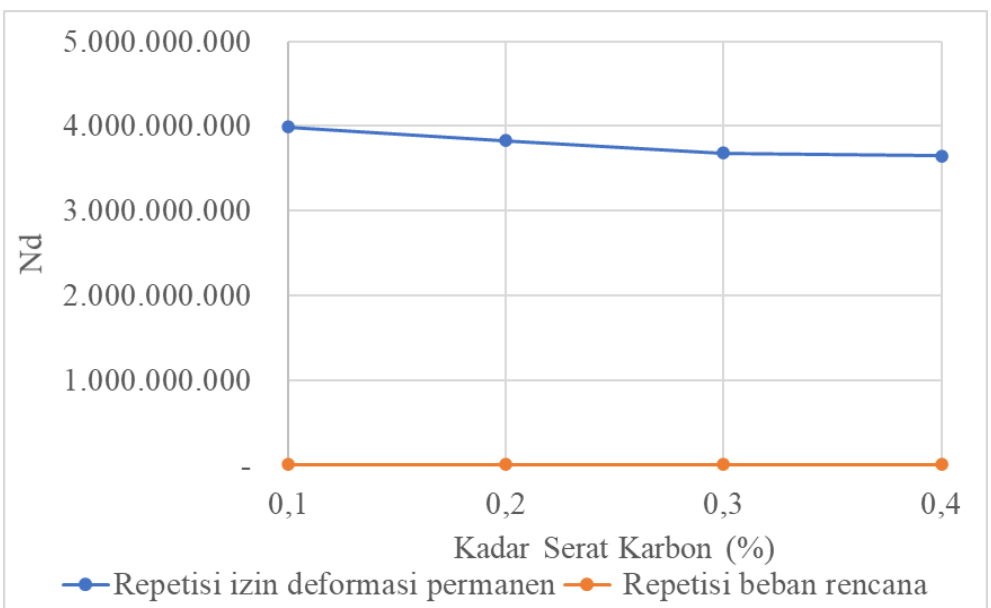

Gambar 8. Hubungan kadar serat karbon dalam campuran dengan nilai Nd pada perkerasan FFF1

Berdasar tabel 9 dan gambar 7 dan 8, nilai Nd terus menurun seiring dengan bertambahnya kadar serat karbon sedangkan nilai Nf terus meningkat seiring dengan bertambahnya kadar serat karbon. Nilai Nd menunjukan batas repetisi beban kerusakan rutting sedangkan nilai Nf menunjukan batas repetisi beban kerusakan fatigue. Pada perkerasan FFF1 untuk variasi penggunaan serat karbon yang berbeda - beda yaitu dengan penambahan $0,1 \% ; 0,2 \%$; 0,3\%; dan 0,4\% serat karbon tidak mengalami kerusakan rutting dan kerusakan fatigue karena nilai Nd dan nilaf $\mathrm{Nf}$ yang dihasilkan tidak kurang dari repetisi rencana (Nr) perkerasan FFF1 sesuai dengan Manual Desain Perkerasan Jalan 2017 yaitu sebesar 2.000.000. 


\section{KESIMPULAN DAN DARAN}

\section{Kesimpulan}

Berdasarkan penelitian yang telah dilakukan dapat disimpulkan sebagai berikut:

1. Penggunaan serat karbon pada penelitian ini menyebabkan nilai VITM meningkat seiring dengan bertambahnya kadar serat karbon. Hal ini disebabkan oleh sifat fisik dari serat karbon itu sendiri, yaitu termoplastik menjadi penyebab serat karbon akan meleleh saat dipanaskan dan menggumpal sehingga menyebabkan pelekatan antar agregat terhalang oleh serat karbon yang menggumpal.

2. Penggunaan serat karbon pada penelitian ini menyebabkan nilai VMA meningkat seiring dengan bertambahnya kadar serat karbon. Hal ini dikarenakan penambahan serat karbon menyebabkan penggumpalan sehingga menghasilkan jarak antar agregat dan rongga udara sehingga akan meningkatkan nilai VMA.

3. Penggunaan serat karbon pada penelitian ini menyebabkan nilai VFWA menurun seiring dengan bertambahnya kadar serat karbon. Hal itu karena serat karbon yang memiliki sifat termoplastik, sehingga pada saat dipanaskan akan menjadi lunak dan mengeras kemudian aspal akan merekatkan serat karbon yang satu dengan yang lain menyebabkan terjadinya gumpalan yang menghalang aspal untuk mengisi seluruh rongga pada campuran.

4. Pada penelitian ini nilai stabilitas menurun seiring dengan bertambahnya kadar serat karbon. Hal ini terjadi karena sifat termoplastik dari serat karbon yang cenderung mengakibatkan pengumpalan sehingga mendapatkan hasil yang kurang stabil.

5. Nilai flow pada penelitian ini cenderung naik seiring bertambahnya kadar serat karbon.

6. Nilai MQ pada penelitian menurun seiring dengan penambahan penggunaan serat karbon. Hal ini menunjukkan bahwa semakin banyak serat karbon yang digunakan, maka perkerasan akan semakin elastis.

7. Pada perkerasan FFF1 untuk variasi penggunaan serat karbon yang berbeda - beda yaitu dengan penambahan $0,1 \% ; 0,2 \% ; 0,3 \%$; dan $0,4 \%$ serat karbon tidak mengalami kerusakan fatigue atau kerusakan rutting karena nilai $\mathrm{Nf}$ dan $\mathrm{Nr}$ yang di hasilkan tidak kurang dari repetisi rencana $(\mathrm{Nr})$.

8. Kadar serat karbon optimum dari penelitian ini adalah $0,225 \%$ yang didapatkan dari metode Narrow Range.

\section{Saran}

Berdasarkan penelitian yang sudah dilakukan didapatkan saran, yaitu:

1. Dikarenakan kesulitan yang disebabkan banyaknya serat karbon yang dimasukkan, maka terjadi penggumpalan pada sampel, sehingga aspal yang seharusnya mengisi rongga udara malah terhalang oleh gumpalan serat karbon, hal ini dapat mengganggu nilai stabilitas campuran. Maka seharusnya pada saat memasukkan serat karbon sebaiknya tidak dimasukkan secara bersamaan.

2. Perlunya penelitian yang lebih lanjut menggunakan bahan tambah serat karbon dan kadar aspal dengan jumlah yang lebih banyak.

3. Range serat karbon yang kurang signifikan, diperlukan penelitian yang lebih lanjut dengan range serat karbon yang lebih jauh agar dapat lihat perbedaan hasilnya.

4. Perlunya penelitian lebih lanjut mengenai nilai stabilitas yang dikonversikan menjadi modulus elastisitas.

\section{DAFTAR PUSTAKA}

Amiruddin. Kajian Eksperimental Campuran HRS-WC dengan Aspal Minyak dan Penambahan Aditif Lateks Sebagai Bahan Pengikat. Jakarta: Universitas Trisakti, 2012.

Departemen Pekerjaan Umum. Spesifikasi Umum Bina Marga. Jakarta: Bina Marga, 2018.

Departemen Pekerjaan Umum. Spesifkiasi Umum Bina Marga. Jakarta: Bina Marga, 2017.

Hardiyatmo, Hary Christady. Aspal Untuk Pemeliharan. Yogyakarta: Gadjah Mada Unviersitas Press, 2015.

Saodang, Hamirhan. Konstuksi Jalan Raya. Bandung: Nova, 2005.

Shanbara, Hayder Kamil. Effect of Carbon Fiber on The Performance of Reinforced Asphalt Concrete Mixture. Samawah: Universitas Al-Muthanna, 2011.

Sutrisno. Analisa Sifat dan Ketahan Bakar Nano Komposit Geomaterial Serat Karbon Phenolyc. Thesis. 2015: Universitas Brawijaya, 2015.

Tenriajeng, Andi Tenrisukki. Laston Sebagai Bahan Alternatif Pekerjaan Pelapisan Jalan. Jakarta: Universitas Gunadarma, 2002.

Wahjoedi. Karakteristik Marshall dan Indeks Kekuatan Sika (IKS) Pada Campuran Butonite Mastic Asphalt (BMA). Semarang: Politeknik Negeri Semarang, 2009. 
